\title{
The Effects of Making Horcitultural Products and Selling Activities on Vocational Rehabilitation of Persons with Mental Disabilities
}

\author{
Ga Ae Seol, Suk Young Yun*, and Byung Jin Choi \\ Department of Horticulture, Daegu Catholic University, Gyeongsan 38430, Korea
}

\begin{abstract}
This study carried out a horticultural program for people with mental disabilities to determine suitability of the horticultural activity program and to actually apply to vocational rehabilitation. The program was carried out in 16 sessions from April 12 to June 7, 2018 with nine people with a strong will to participate in vocational rehabilitation at a health center for persons with mental disabilities. The tools used were the Horticultural Activity Performance Assessment (psychological behavior) and Purdue Pegboard Test that examines functions of hands and arms. The subjects sold the products they made during class time and obtained the profits. After the program, the scores increased with a significant difference $(p=.000)$ in the psychological behavior area of the Horticultural Activity Performance Assessment. Hand and arm movement also showed continuous improvement along the program with a significant difference $(p=.000)$, as well as finger dexterity also with a significant difference $(p=.018)$. The net profit was $314,000 \mathrm{KRW}$ (subtracting cost of goods $314,000 \mathrm{KRW}$ from total sales 628,000 KRW). The profit was shared equally among the nine subjects, each receiving 34,900 KRW. Therefore this study proved horticultural activity class is suitable for vocational rehabilitation of people with mental disabilities proved by the positive effects. We also expect that the subjects will be able to make more profits if they learn more skills, since they are interested the process of making such profits.
\end{abstract}

Keywords: finger dexterity, income, profit, psychological behavior

\section{Introduction}

Occupation is a means for human beings to maintain livelihood by earning income and goods, and individuals volunteer and participate in the society by sharing the duties of the community. Without labor as the driving force of social development and key to human life, it is difficult to guarantee a living worthy of human dignity. The Constitution also ensure the rights and obligations for human beings to work. A job that fits has more significance than just a means of subsistence, enabling one to develop their talent and experience pride and self-achievement (Cho et al., 2007).

However, people with mental or physical disabilities are relatively in a poor situation in enjoying occupational

Received: April 10, 2019, Revised: April 18, 2019, Accepted: June 3, 2019

First author: Ga Ae Seol, E-mail: sko475@hanmail.net, (D) https://orcid.org/000-0002-3612-705X

*Corresponding author: Suk Young Yun, E-mail: yunesy@hanmail.net, (1) https://orcid.org/0000-0002-5862-0021 
life due to social prejudice or have difficulty in seeking a job in the first place. In the end, persons with disabilities excluded from occupation cannot stand on their own feet, which gradually deteriorates the quality of their lives (Lee et al., 2003). Moreover, those impossible to have an independent life need the help of family, society or someone, which leads to another burden. It is a very important challenge to reduce this kind of burden and enable them to have jobs to guarantee a living worthy of human dignity (Cho et al., 2007). For persons with mental disorders, getting a job is fulfilling economic and social independence away from the dependent life and having the chance to contribute to the society as a member, and even fulfill self-realization by increasing their value of existence and dignity with guaranteed life as a human being (Lee and Hwang, 2012). In rehabilitation for persons with disabilities, the key challenge is to enable persons with disabilities to enjoy an independent life for their successful social integration. Vocational rehabilitation is the flower of rehabilitation that guarantees their rights and obligations to work by finding and maximizing their physical, mental, social, vocational and economic abilities (McGowan, 1969).

Horticultural therapy defined by Korean Horticultural Therapy Association refers to overall activities that develop social, educational, psychological or physical adaptability through various horticultural activities of humans using plants and seek physical rehabilitation and mental recovery. Recently, horticultural therapy is specifically defined as specialized activities that pursue mental and physical recovery and rehabilitation of participants with horticultural therapists determining their diseases or disabilities, set therapeutic goals that are intentional and achievable, and achieving them through various programs. Plants and soil, which are materials used in horticultural therapy, are natural objects that are often encountered in everyday life, which are more accessible than the conventional therapeutic approaches and more natural in terms of process, thereby minimizing stress (Lee et al., 2016).

Previous studies that applied horticultural therapy to rehabilitation of persons with disabilities include Doxon et al. (1987) who claimed that persons with intellectual disabilities showed a decrease in stress after horticultural training, and Bang and Kim (2004) who proved that horticultural activities are effective in reducing maladaptive behavior of children with intellectual disabilities by reducing their aggression, withdrawn behavior and hyperactivity. Kim and So (2011) argued that horticultural therapy applying a repeated floral design program improved work performance and hand function of persons with intellectual disabilities. Lee et al. (2007) carried out a horticultural therapy program using floral design functional training on students with intellectual disabilities and proved that this improved work performance capacity and had a positive effect on work adjustment and vocational rehabilitation.

In previous studies, horticultural therapy was proved to have a positive effect on vocational rehabilitation of persons with disabilities, but there were not many concrete studies that applied to actual job settings.

Therefore, this study carried out various horticultural programs for persons with mental disorders to verify the suitability of horticultural activities as vocational rehabilitation and identify specific programs that are applicable to the work settings. To this end, we had the subjects learn the horticultural product making skills and make such products themselves, thereby evaluating psychological behavior and hand dexterity of persons with mental disorders after horticultural activities by product and session and determining the value as vocational rehabilitation by analyzing the proceeds from the sale.

\section{Research Methods}

\section{Subjects}

This study was conducted on nine persons with mental disorders that are members of a health center located in G city of Gyeongsangbuk-do who have a strong will to do vocational rehabilitation after obtaining consent from 
the head of the Mental Health Welfare Center and the subjects. The subjects were persons with mental disorders, five males and four females, with symptoms of schizophrenia1), depression'2), and schizoaffective disorders ${ }^{3}$ ) with the average age of $38.9 \pm 9.5$.

\section{Research tools}

\section{Program design}

This study was conducted in total 16 sessions from April 12 to June 7, 2018. A pretest was conducted before the horticultural activities on April 12, and the program was carried out from April 16 to June 7 twice a week for two hours per session on Mondays and Thursdays. It was led by the welfare horticultural therapist registered-grade I certified by Korean Horticultural Therapy Association, assisted by one welfare horticultural therapist registered-grade II. The goal was to verify the specific possibility of whether horticultural programs can be applied to persons with mental disorders as an occupation. To achieve the goal, the program was focused on having the participants accurately understand and learn the skills beyond just receiving horticultural therapy.

For the program, we selected eight types of products that show high sales in flower shops, and had the subjects learn the skills for each product and then make and sell the product in the following session. In Sessions 1, 3, 5, 7, 9, 11, 13, 15 , they repeatedly practiced one program in three levels for each session to learn the skills. The level of difficulty was adjusted by giving variations to the amount of materials in each level. Level 1 was a simple task using minimum amount of materials, whereas Levels 2 and 3 required them to produce output with merchantability by increasing the amount of materials. In Sessions 2, 4, 6, 8, 10, 12, 14, 16, the subjects made the horticultural products for actual sale as before they practiced.

Activities included wrapping pots in Session 1, making flower baskets in Session 3, making corsages in Session 5, wrapping a single flower in Session 7, planting Dracaena sanderiana in Session 9, planting Sansevieria stuckyi in Session 11, making a herbarium in Session 13, and making dry flower cards in Session 15. The materials were purchased with material costs at the flower shops, and some of the finished products were sold at the café run by members of the vocational rehabilitation in the health center, and some of them were sent to the flower shops to generate proceeds (Table 1).

\section{Assessment tools}

(1) Horticultural Activity Performance Assessment (psychological behavior)

To assess the horticultural activity performance of persons with mild and moderate intellectual disabilities, we used the Korean version of the Horticultural Activity Performance Assessment developed by Kim et al. (2004) comprised of total 84 items in categories such as cognition, perceptual motor, social skills interaction and psychological behavior. The tool is rated by the horticultural therapist on a 5-point Likert scale from strongly agree (5 points) to strongly disagree (1 point), and negative items are inverse-calculated (Lee et al., 2007). This study assessed psychological behavior comprised of total 29 items in nine factors: five items in interest and attention, five items in problematic behavior, four items in participation, three items in confidence, three items in sensitivity, three items in dependency, two items in

\footnotetext{
1) Mental disorder that causes extensive clinical abnormalities in various aspects of personality such as thinking, emotion, perception and behavior 2) Disease in which the overall state of deteriorated mental functions such as thought, thinking process, motivation, will, interest, behavior, sleep and physical activity appear all day or every day

3) Disease in which the major symptoms of schizophrenia diagnosis are accompanied by mood disorders (depression, mania, or mixed type) for some time
} 
Table 1. Horticultural activity program and materials used for this experiment

\begin{tabular}{|c|c|c|c|c|}
\hline \multirow{2}{*}{ Session } & \multirow{2}{*}{ Activity } & \multirow{2}{*}{ Level } & \multicolumn{2}{|c|}{ Materials used } \\
\hline & & & Plant material & Non-plant material \\
\hline \multirow{3}{*}{1} & \multirow{4}{*}{$\begin{array}{l}\text { Wrapping } \\
\text { carnation pots }\end{array}$} & 1 & Dianthus caryophyllus & OPP film, tape \\
\hline & & 2 & Dianthus caryophyllus & OPP film, tape, wrapping paper \\
\hline & & 3 & Dianthus caryophyllus & OPP film, tape, wrapping paper, dry flower \\
\hline 2 & & Production & Dianthus caryophyllus & OPP film, tape, wrapping paper, dry flower \\
\hline \multirow{3}{*}{3} & \multirow{4}{*}{$\begin{array}{l}\text { Making } \\
\text { mini flower } \\
\text { baskets }\end{array}$} & 1 & $\begin{array}{l}\text { Dianthus caryophyllus, } \\
\text { Chamaecyparis obtusa }\end{array}$ & Floral foam, basket \\
\hline & & 2 & $\begin{array}{l}\text { Dianthus caryophyllus, } \\
\text { Chamaecyparis obtusa, } \\
\text { Limonium sinensis }\end{array}$ & Floral foam, basket \\
\hline & & 3 & $\begin{array}{l}\text { Dianthus caryophyllus, } \\
\text { Chamaecyparis obtusa, } \\
\text { Limonium sinensis }\end{array}$ & Floral foam, basket, ribbon, accessory \\
\hline 4 & & Production & $\begin{array}{l}\text { Dianthus caryophyllus, } \\
\text { Chamaecyparis obtusa, } \\
\text { Limonium sinensis }\end{array}$ & Floral foam, basket, ribbon, accessory \\
\hline \multirow{3}{*}{5} & \multirow{4}{*}{$\begin{array}{l}\text { Making } \\
\text { corsages }\end{array}$} & 1 & Dianthus caryophyllus & Floral tape \\
\hline & & 2 & Dianthus caryophyllus & Floral tape, leaf \\
\hline & & 3 & Dianthus caryophyllus & Floral tape, leaf, ribbon, clothing pin \\
\hline 6 & & Production & Dianthus caryophyllus & Floral tape, leaf, ribbon, clothing pin \\
\hline \multirow{3}{*}{7} & \multirow{4}{*}{$\begin{array}{l}\text { Wrapping } \\
\text { a single flower }\end{array}$} & 1 & Rosa hybrida & OPP film, tape \\
\hline & & 2 & Rosa hybrida & OPP film, tape, ribbon \\
\hline & & 3 & Rosa hybrida & OPP film, tape, ribbon, wrapping paper \\
\hline 8 & & Production & Rosa hybrida & OPP film, tape, ribbon, wrapping paper \\
\hline \multirow{3}{*}{9} & \multirow{4}{*}{$\begin{array}{l}\text { Planting } \\
\text { sander's } \\
\text { dracaena }\end{array}$} & 1 & Dracaena sanderiana & Bottle \\
\hline & & 2 & Dracaena sanderiana & Bottle, stone \\
\hline & & 3 & Dracaena sanderiana & Bottle, stone, jute rope \\
\hline 10 & & Production & Dracaena sanderiana & Bottle, stone, jute rope \\
\hline \multirow{3}{*}{11} & \multirow{4}{*}{$\begin{array}{l}\text { Planting } \\
\text { snake plants }\end{array}$} & 1 & Sansevieria stuckyi & Pot, soil, pumice soil \\
\hline & & 2 & Sansevieria stuckyi & Pot, soil, pumice soil, color stone \\
\hline & & 3 & Sansevieria stuckyi & Pot, soil, pumice soil, color stone, egg stone \\
\hline 12 & & Production & Sansevieria stuckyi & Pot, soil, pumice soil, color stone, egg stone \\
\hline \multirow{3}{*}{13} & \multirow{4}{*}{$\begin{array}{c}\text { Making } \\
\text { a herbarium }\end{array}$} & 1 & Gypsophila elegans & \\
\hline & & 2 & Gypsophila elegans & Bottle \\
\hline & & 3 & Gypsophila elegans & Bottle, herbarium solution \\
\hline 14 & & Production & Gypsophila elegans & Bottle, herbarium solution \\
\hline \multirow{3}{*}{15} & \multirow{4}{*}{$\begin{array}{c}\text { Making } \\
\text { dry flower cards }\end{array}$} & 1 & & Craft paper, scissors \\
\hline & & 2 & & Craft paper, scissors, namepen \\
\hline & & 3 & Dry flowers & Craft paper, scissors, namepen, masking tape \\
\hline 16 & & Production & Dry flowers & Craft paper, scissors, namepen, masking tape \\
\hline
\end{tabular}


mental instability, two items in intimidation, and two items in frustration. For comparison among activities, the assistant observed the subjects' participation attitudes and behaviors every Thursday.

\section{(2) Hand dexterity (Purdue Pegboard Test)}

The Purdue Pegboard Test is a tool developed by Joseph Tiffin in 1948, industrial psychologist at Purdue University, to select workers on industrial sites. The Purdue Pegboard measures overall movements of fingers, hands and arms as well as hand dexterity such as elaborate functions of fingertips, and it is used as a tool acknowledged by vocational evaluators to verify the vocational abilities of interviewees in many vocational rehabilitation centers for persons with disabilities (Kang, 2004). This study used the revised version (model 32020) by Lafayette Instrument, which is used in vocational evaluation at the Korea Employment Agency for the Disabled. The test was first demonstrated by the evaluator and started after the subjects accurately understood through practice. It is in the order of dominant hand, non-dominant hand, both hands, and assembly, measured three times each. The time limit is 30 seconds for dominant hand, non-dominant hand and both hands, and 60 seconds for assembly. The test began with the "start" signal and ended with "stop" signal, and the tools dropped during the task were to be left as they are until the end of the test (Kim, 2012). Once the class was over, the assistant and subject sat down face to face for assessment according to the criteria. This assessment is carried out one-on-one between the assistant and the subject, thereby requiring a long time to assess all subjects every session. Thus, the measurement was performed three times in this study: before, during and after the program.

\section{Data analysis}

In this study, changes in horticultural activity performance and hand dexterity were analyzed using repeated measures design ANOVA with the SPSS WIN 18.0 program to determine the effectiveness of each product in each session by performing assessment after making the products.

\section{Results and Discussion}

\section{Changes in psychological behavior}

To determine the changes in psychological behavior after horticultural activities, we assessed the results every time the outputs for sale were completed. As a result, the mean scores gradually increased from $95.2 \pm 8.9$ points after wrapping pots in Sessions 1-2 to 97.9 \pm 7.7 points after making flower baskets in Sessions 3-4, 106.6 \pm 9.8 points after making corsages in Sessions 5-6, 113.9 \pm 9.6 points after wrapping a single flower in Sessions 7-8, 115.6 \pm 8.3 points after planting Dracaena sanderiana in Sessions 9-10, 122.1 \pm 4.6 points after planting Sansevieria stuckyi in Sessions $11-12,130.0 \pm 4.1$ points after making a herbarium in Sessions $13-14$, and finally $129.9 \pm 6.5$ points after making cards in Sessions 15-16. The sphericity is met as a result of the sphericity test, with a significant difference at $p=$ .000 under the assumption of sphericity (Table 2). The scores tended to somewhat decrease after making cards but increased overall, especially after making corsages, wrapping a single flower and planting Sansevieria stuckyi. This is consistent with the study results by Shim et al. (2008) that persons with intellectual disabilities showed less anxiety and more sociality after a horticultural therapy program, and by Son et al. (2001) that high school students in a special class showed increased confidence and sense of achievement and decreased anxiety after participating in a horticultural therapy class as they tended, cultivated or exchanged gifts of their outputs with family. Various new horticul- 
tural activities stimulated curiosity and interest among persons with mental disorders in materials and classes, increased expectancy for the next class, and improved confidence and independence by touching objects with hands and completing works on their own. Studies on vocational rehabilitation of persons with mental disorders in Korea had been mostly focused on whether persons with mental disorders succeeded in employment, whereas recently studies on maintaining their jobs and vocational rehabilitation are conducted actively (Nam and Chae, 2009). The final goal of vocational rehabilitation is achieved only by continuously maintaining vocational life even after getting a job. Lee (2003) analyzed the factors affecting job retention of persons with mental disorders and discovered that psychological factors had effect on the job retention period. Since horticultural activity performance in this study improved interest, expectancy and confidence of persons with mental disorders, it will also have positive effects on vocational rehabilitation and job retention.

\section{Changes in hand function}

The overall movements of hands and arms measured by the mean of the sum of dominant hand, non-dominant hand and both hands were assessed before the horticultural activities, after Session 8, and after Session 16. The number of movements increased from $32.7 \pm 7.0$ before to $35.1 \pm 7.5$ during and $37.1 \pm 7.7$ after the program, and the sphericity was met as a result of the sphericity test, with a significant difference at $p=.000$ under the assumption of sphericity (Table 3). As a result of assembly to measure finger dexterity, there was an increase from $23.5 \pm 9.3$ before to $26.0 \pm 11.0$ during and 27.0 \pm 11.0 after the program, and the sphericity was met as a result of the sphericity test, with a significant difference at $p=.018$ under the assumption of sphericity (Table 3 ). This is consistent with the study results by Kim and

Table 2. Changes in psychological behavior after horticultural activity

\begin{tabular}{lcc}
\hline Session & Activity & Score (M \pm SD) \\
\hline $1-2$ & Wrapping carnation pots & $95.2 \pm 8.9$ \\
$3-4$ & Making mini flower baskets & $97.9 \pm 7.7$ \\
$5-6$ & Making corsages & $106.6 \pm 9.8$ \\
$7-8$ & Wrapping a single flower & $113.9 \pm 9.6$ \\
$9-10$ & Planting lucky bamboo plants & $115.6 \pm 8.3$ \\
$11-12$ & Planting snake plants & $122.1 \pm 4.6$ \\
$13-14$ & Making a herbarium & $130.0 \pm 4.1$ \\
$15-16$ & Making dry flower cards & $129.9 \pm 6.5$ \\
\hline
\end{tabular}

${ }^{* * *} p<.001$ by repeated measures design ANOVA.

Table 3. Changes in hand function along the horticultural activity (HA) program

\begin{tabular}{|c|c|c|c|c|}
\hline \multirow{2}{*}{ Item } & \multicolumn{3}{|c|}{$\mathrm{M} \pm \mathrm{SD}$} & \multirow{2}{*}{$p$} \\
\hline & Pre-HA & Mid-HA & Post-HA & \\
\hline Movement of hands and arms & $32.7 \pm 7.0$ & $35.1 \pm 7.5$ & $37.1 \pm 7.7$ & $.000^{* * * *}$ \\
\hline Finger dexterity & $23.5 \pm 9.3$ & $26.0 \pm 11.0$ & $27.0 \pm 11.0$ & $.018^{*}$ \\
\hline
\end{tabular}

${ }^{*} p<.05,{ }^{* * *} p<.001$ by repeated measures design ANOVA. 
So (2011) that horticultural therapy applying a repeated floral design program improved hand function of persons with intellectual disabilities. In Korea, it is important for persons with disabilities to acquire working techniques and skills to perform their tasks on their own without a supervisor in order to maintain a normal career (Kim, 1997). Chang et al. (2005) stated that occupational therapy to improve hand function of persons with intellectual disabilities enhanced not only hand function but also work performance. Horticultural activities stimulated fine and gross motor skills and improved upper-limb coordination of hands and arms of persons with mental disorders as well as finger dexterity, thereby anticipating effect in acquisition of skills and work performance increase during vocational rehabilitation of persons with mental disorders.

\section{Proceeds from sale of horticultural products}

Among total eight products, the herbariums were destroyed while displaying them at the health center for sale, and all were recalled considering the safety of the subjects. All seven other products except the herbariums required total 314,000 KRW to purchase materials and turned over 628,000 KRW in sales through delivery and sale. The net profit was 314,000 KRW, which was shared equally among the nine subjects, each earning 34,900 KRW (Table 4). The proceeds are determined just by comparing the material costs and sales, so the profits that can be actually obtained by the subjects may be smaller if detailed elements like shipping costs and labor costs are also considered. However, the significance was in the fact that products made by persons with mental disorders were actually sellable to consumers and proved that they can participate in economic activities. In fact, the subjects frequently asked questions about the proceeds in class and showed interest, and seemed excited as they shared the proceeds. Recently, the margins of facilities selling products made by persons with disabilities have increased from 3.8 billion KRW in 2012 to 4.9 billion KRW in 2015. The purpose of such facilities is to display the function of vocational rehabilitation by promoting sales of products and services through vocational rehabilitation of persons with disabilities, while also contributing to the improved perception on disabilities (Baek, 2016). This study verified the applicability of horticultural products as vocational rehabilitation of persons with mental disorders. Thus, the results can be developed more realistically by seeking adequate pricing methods and systemizing working techniques considering various distribution structures. However, most subjects could not afford products that require high material costs. Consumers also easily

Table 4. Proceeds from sales of horticultural products (unit: KRW)

\begin{tabular}{lccc}
\hline Item & Cost of goods & Total sales & Net profit \\
\hline Paper-wrapped carnation pots & 54,000 & 108,000 & 54,000 \\
Mini flower baskets & 50,000 & 100,000 & 50,000 \\
Corsages & 30,000 & 60,000 & 30,000 \\
Single rose bouquet & 27,000 & 54,000 & 27,000 \\
Sander's dracaena plants in pot & 18,000 & 36,000 & 18,000 \\
Snake plants in pot & 126,000 & 252,000 & 126,000 \\
Herbarium & - & - & - \\
Dry flower cards & 9,000 & 18,000 & 9,000 \\
Total & 314,000 & 628,000 & 314,000 \\
\hline
\end{tabular}


purchased inexpensive products, whereas high-priced products showed poor sales. This led to concern and anxiety among the subjects. Products made in glass such as herbariums had a risk of accident. Thus, it is important to select products and materials with low costs and prices that are simple to make, have high stability, and are easy to manage, considering the situation of the subjects in vocational rehabilitation of persons with mental disorders.

\section{Conclusion}

To determine a realistically suitable program for vocational rehabilitation of persons with mental disorders by applying various horticultural programs to the vocational rehabilitation horticultural class, this study conducted 16 sessions of the horticultural program from April 12 to June 7, 2018 with nine persons with mental disorders in the vocational rehabilitation class at the health center of $\mathrm{G}$ city, Gyeongsangbuk-do. We measured the changes in psychological behavior, hand and arm movements, and hand dexterity of fingertips. As the subjects proceeded with the sessions, their psychological behavior was improved with a significant difference $(p=.000)$. as well as hand and arm movement $(p=.000)$ and finger dexterity $(p=.018)$ with a significant difference, thereby proving that horticultural activities had positive effects on the mind and body of persons with mental disorders. Furthermore, the subjects could actually gain profits, even though the amount was small, by actually purchasing materials, making horticultural products and selling them, showing extremely high level of satisfaction and interest in the process. The number of samples in this study is small since this study was conducted in only one health center of a specific area, and thus the results are not suitable for generalization. However, the results of this study can be provided as the basic data of relevant research in anticipation for more systematic and sustainable programs that can be applied to vocational settings. We suggest using a greater number of samples in future research to verify effectiveness of the results and anticipate continuous research on application of horticultural activities to vocational rehabilitation.

\section{References}

Baek, E.S. 2016, June. Performance and improvement of facilities for sale of products for the disabled. Proceedings of Annual Conference on Vocational Rehabilitation (Korean Society of Vocational Rehabilitation). 2016(6):53-57.

Bang, G.H and J.H. Kim. 2004. The effect of horticultural therapy on the maladjusted behavior of children with mental retardation. J. Agric. Educ. Hum. Resour. Dev. 36(1):49-68. Retrieved from http://www.agedhrd.or.kr

Chang, K.Y., W.H. Kim, and C.W. Han. 2005. The effects of occupational activity program for hand function and occupational performance ability on mentally retarded adults. J. Voca. Rehabil. 15(2):213-233. Retrieved from http://www.ksvr.or.kr

Cho, H.K., Y.B. Lee, and S.J. Jeong. 2007. Effect of horticultural therapy program on the vocational rehabilitation of mentally handicapped adults. J. Korean Soc. People Plants Environ. 10(4):155-161.

Doxon, L.E., R.H. Mattson. and A.P. Jurich 1987. Human stress reduction through horticultural vocational training. HortScience 22(4):655-656.

Kang, Y.J. 2004. Purdue Pegboard standardization for vocational evaluation of the disabled: Implementation and interpretation. Disabil. Employ. 14(4):85-96. Retrieved from https://edi.kead.or.kr

Kim, J.H. 2012. Effect of horticultural occupational therapy utilizing a floral arrangement on vocational-achievement ability of chronic schizophrenia patients. Master's thesis, University of Seoul, Seoul, Korea.

Kim, K.S and I.S. So. 2011. The effect of the horticultural therapy using repetitive-floricultural- decoration program on the improvement in work performance and hand skills of the intellectually handicapped. J. Asian Agric. Biotechnol. [Jeju National University] 27(1):27-37.

Kim, N.E., K.C. Son, and M.K. Kim. 2004. Development of horticultural activity performance assessment(HAPA) for 
mild and moderate mentally retarded people (Abstr.). Korean J. Hortic. Sci. Technol. 22(Suppl. 1):42.

Kim, S.S. 1997. Emploger's rankings of factors judged critical to job success for individuals with disabilities. J. Spec. Educ. Rehabil. [Kongju National University] 3(1):133-151.

Lee, D.Y., S.W. Lee, and H.J. Park. 2003. A study on the variables influencing the awareness level of vocational rehabilitation services among persons with psychiatric disabilities, their families, and rehabilitation staff. J. Voc. Rehabil. 13(1):147-168. Retrieved from http://www.ksvr.or.kr

Lee, E.M and K.R. Hwang. 2012. Effect of mentally challenged persons' satisfaction with vocational rehabilitation and job position on contentment with life. Korean J. Phys. Mult. Health Disabil. 55(1):93-106.

Lee, G.S., S.Y. Yun, H.S. Choi, and B.J. Choi. 2016. The effect of horticulture therapy program applied a color stimulus on the change of challenging behaviour of developmental disabilities (Abstr.). J. Korean Soc. People Plants Environ. 19(5, Suppl. 2):195.

Lee, K.J. 2003. A study on the factors affecting on the duration of job maintenance for people with psychiatric disabilities. Disabil. Employ. 13(4):21-51. Retrieved from https://edi.kead.or.kr

Lee, S.J., S.J. Um, J.E. Song, and K.C. Son. 2007. Effect of horticultural therapy using the floral decoration training on the improvement of occupational performance ability and vocational rehabilitation in mentally retarded. Korean J. Hortic. Sci. Technol. 25(4):474-484.

McGowan, J.F. 1969. Referral, evaluation and treatment. In D. Malikin and H. Rusalem (Eds.), Vocational rehabilitation of the disabled: An overview. New York, NY: New York University Press.

Nam, Y.H and I.S. Chae. 2009. A study on the job maintenance for the worker with mental disorder. J. Voc. Rehabil. 19(1):187-201. Retrieved from http://www.ksvr.or.kr

Shim, Y.E., J.K. Suh, and S.H. Lee. 2008. Effect of horticultural therapy program for improvement of work adjustment skill in people with mental retardation. J. Voc. Rehabil. 18(2):89-115. Retrieved from http://www.ksvr.or.kr

Son, K.C., H.J. Jung, J.Y. Koo, H.J. Bae, and M.K. Kim. 2001. Effect of horticultural therapy on the changes of selfesteem and anxiety of special classes in high school (Abstr.). Korean J. Hortic. Sci. Technol. 19(Suppl. 2):35. 